\title{
Percepção da equipe multiprofissional sobre cuidados paliativos
}

\author{
Perception of multiprofessional staff of palliative care
}

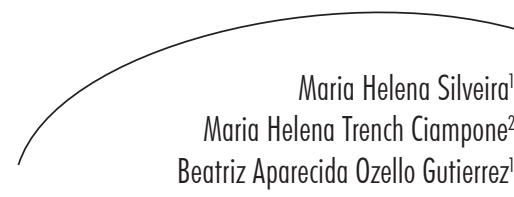

\section{Resumo}

Este estudo teve como objetivos investigar os significados apresentados pela equipe multiprofissional e identificar o prazer e o sofrimento no trabalho em cuidados paliativos. A pesquisa qualitativa realizou-se em unidade hospitalar de cuidados paliativos no município de São Paulo. Foram entrevistados 18 indivíduos da equipe multiprofissional paliativista que assistem a idosos e seus familiares. A coleta de dados ocorreu por meio de entrevistas individuais gravadas e direcionadas por questões abertas e semiestruturadas. Os dados foram analisados pela proposta de análise temática elaborada por Minayo, fundamentada nos preceitos de prazer e sofrimento no trabalho determinado por Dejours. Os relatos foram classificados em três categorias: significados apresentados pelos profissionais relacionados ao trabalho, apontados em três subcategorias: humanização; satisfação pessoal; e profissional no processo do cuidar. A segunda categoria decorrente do prazer no trabalho contou com as subcategorias: qualidade da assistência prestada aos familiares, assim como aos pacientes em cuidados paliativos; e fontes de prazer relacionadas à equipe multiprofissional. A terceira categoria, marcada pelo sofrimento da equipe, incluiu as subcategorias: presença do processo de morrer e da morte; desgaste decorrente do sofrimento do paciente; e impotência e presença de conflitos na equipe multiprofissional de cuidados paliativos. Os resultados mostram a importância do prazer no trabalho e direcionam alguns aspectos que podem ser revistos visando à superação do sofrimento e ao alcance da dignidade, ao atuar em cuidados paliativos.

\footnotetext{
Curso de Gerontologia, Escola de Artes, Ciências e Humanidades. Universidade de São Paulo. São Paulo, SP, Brasil.

2 Departamento de Orientação Profissional, Escola de Enfermagem. Universidade de São Paulo. São Paulo, SP, Brasil.
}

Palavras-chave: Idosos. Cuidados paliativos. Equipe de assistência ao paciente. Saúde do trabalhador. 


\section{Abstract}

This study aimed to investigate the meanings presented by the multidisciplinary team and identify pleasure and suffering at work in palliative care. This qualitative research took place in a hospital unit of palliative care in the city of São Paulo. Eighteen individuals of multidisciplinary palliative care team whocassisting elderly and their families were interviewed. Data were collected through individual interviews recorded and directed by semi-structured and open questions. Data were analyzed through Minayo's thematic analysis, based on the precepts of pleasure and pain at work determined by Dejours. The reports were classified into three categories: meanings presented by the professionals related to work, divided into three subcategories: humanization; personal and professional satisfaction in the care process The second category resulting of pleasure at work featured subcategories: quality of care provided to patients and family members in palliative care; and sources of pleasure related to the multidisciplinary team. The third category, marked by suffering of the team, included the subcategories: presence of the dying process and death; the wear and tear of the patient's suffering; helplessness and the presence of conflict in the multidisciplinary palliative care team. The results of this research show the importance of pleasure in work and direct some aspects that can be reviewed with a view to overcoming suffering and the achievement of dignity to work in palliative care.
Key words: Elderly. Palliative Care. Patient Care Team. Occupational Health.

\section{INTRODUÇÃO}

O Brasil vem experimentando acentuado envelhecimento populacional, causado pela mudança drástica nos perfis demográfico e epidemiológico da população. Para esse novo panorama populacional, deve-se levar em conta que a velhice é fator de risco para o desenvolvimento de doenças e que o avanço tecnológico, algumas vezes, pode acarretar condições inadequadas na vida das pessoas. Esse avanço na área da tecnologia hospitalar vem acompanhado da despersonalização das pessoas, presente sobretudo para aquelas pessoas que estão próximas da morte.

Os efeitos da tecnociência são sabidos de todos e abundantemente proclamados pela mídia. Defrontamo-nos com ambientes perfeitos em sua tecnologia, mas sem alma e ausência de carinho humano. A pessoa vulnerável, devido a sua doença, deixou de ser o centro das atenções e foi instrumentalizada em função de um determinado fim.

Identifica-se que a grande preocupação da maioria dos profissionais de saúde, que assistem a pessoas com a saúde comprometida, está atrelada a tratar ativamente de sua doença, esquecendo-se de cuidar do seu sofrimento e o de seus familiares. No entanto, para tornar esses dias de sobrevida menos árduos, tanto para o paciente portador de doença crônico-degenerativa que está fora de possibilidades terapêuticas, quanto para seus familiares, surgiram os cuidados paliativos. ${ }^{1}$

\section{"Cuidados paliativos" é a abordagem que promove qualidade de vida de pacientes e seus familiares, diante de doenças que ameacam a continuidade da vida, através de prevenção e alivio do sofrimento. Requer a identificação precoce, avaliação e tratamento impecável da dor e outros problemas de natureza física, psicossocial e espiritual. ${ }^{2}$}

Dessa forma, os cuidados paliativos proporcionam alívio da dor e de outros sintomas angustiantes; afirmam a vida e encaram a morte como um processo normal; não pretendem apressar ou adiar a morte; integram os aspectos psicológicos e espirituais da assistência ao paciente; oferecem um sistema de apoio para ajudar os pacientes a viverem ativamente o quanto possível até a morte, além de ajudar a família a lidar com a doença e o luto; usam uma abordagem de equipe para atender às necessidades dos pacientes e suas famílias, incluindo aconselhamento de luto, se 
indicado; melhoram a qualidade de vida e podem também influenciar positivamente o curso da doença. São aplicáveis no início da doença, em conjunto com outras terapias que visam prolongar a vida, como a quimioterapia ou radioterapia, e que incluem as investigações necessárias para melhor compreender e gerenciar complicações clínicas angustiantes. ${ }^{3}$

Nessa mudança de paradigma, em que o foco é cuidar, o enfoque terapêutico visa ao alívio dos sintomas que comprometem a qualidade de vida, integrando ações médicas, de enfermagem, psicológicas, nutricionais, sociais, espirituais e de reabilitação, que influenciam também no tipo de morte que o paciente terá.

E ainda, os cuidados paliativos consideram a família uma unidade de cuidado que também deve receber assistência durante todo o tempo de acompanhamento de seu paciente, prosseguindo até depois de seu óbito, no período de luto. Todavia, para alcançar a excelência nesses cuidados, deverá existir uma equipe de âmbito interdisciplinar e interprofissional, cujas dedicações se quantificarão em função das necessidades concretas de atenção.

Para que essa equipe interprofissional consiga desenvolver seu trabalho com sucesso, tornase imprescindível que a saúde mental de cada integrante seja mantida e aprimorada, uma vez que implica enorme ganho para os próprios profissionais envolvidos com os cuidados do indivíduo no fim da vida, e também para a qualidade desses cuidados oferecidos ao paciente e à família. Nesse cenário, encontramse trabalhadores de diferentes categorias profissionais que geralmente relatam insatisfação perante o trabalho. Essas insatisfações denotam desajustes e até conflitos entre o homem e o resultado do trabalho; na tentativa de amenizálas, têm-se desenvolvido estudos na área da psicologia do trabalho.

O campo da psicologia do trabalho compreende a psicanálise, a psicossociologia e a psicologia abstrata, e atualmente é conhecida como psicodinâmica do trabalho, desenvolvida na França a partir de 1970, e cujo principal representante é o psiquiatra Christophe Dejours. ${ }^{3}$ A análise psicodinâmica das situações de trabalho está relacionada com o estudo dos movimentos psicoafetivos gerados pela evolução dos conflitos intersubjetivos e intrassubjetivos desenvolvidos no ambiente de trabalho. ${ }^{3}$

A intersubjetividade, para a psicodinâmica do trabalho, baseia-se em seu modelo de homem no trabalho, sendo que este homem é virtualmente um indivíduo pensante. Fundamentalmente, o indivíduo pensa na sua relação com o trabalho, interpreta suas condições, socializaas intersubjetivamente, reage e organiza-se mental, afetiva e fisicamente, em função de suas interpretações, atuando sobre seu processo de trabalho, contribuindo assim para a construção e evolução das relações sociais de trabalho. ${ }^{4}$

Nesse sentido, a intersubjetividade refere-se à construção do sentido e à aptidão do sujeito para interpretar sua situação, para decidir, regular e controlar sua ação, identificando a prioridade do qualitativo e do subjetivo na análise da realidade e na atitude científica. Em decorrência desse processo, podem existir o prazer e o sofrimento no trabalho.

O prazer do trabalhador procede da descarga de energia psíquica, carga positiva que a tarefa autoriza, resultando numa diminuição da carga psíquica do trabalho, sendo conhecido como "trabalho equilibrante" - que proporciona o prazer no trabalho. Decorre da utilização da inteligência astuciosa de alguns profissionais, na tentativa de amenizar o sofrimento no trabalho, por meio de estratégias defensivas ou macetes, ocasionando o prazer no trabalho. ${ }^{3}$ Contudo, na medida em que o trabalho é contrário à livre atividade, ele pode ser perigoso ao aparelho psíquico. O acúmulo de energia psíquica, carga psíquica negativa, torna o trabalho uma fonte de tensão e desprazer. Com isso, pode aparecer a fadiga, a astenia, e a partir daí a patologia, nomeada de "trabalho fatigante", acarretando o sofrimento no trabalho. ${ }^{3}$

Esse sofrimento é compreendido pela vivência subjetiva intermediária entre doença mental descompensada e o bem-estar psíquico. 
Existem dois tipos de sofrimento: o sofrimento criador e o sofrimento patogênico. O sofrimento patogênico surge quando não há mais liberdade na transformação, gestão e aperfeiçoamento na organização do trabalho. ${ }^{3}$

Partindo da premissa de que a psicodinâmica do trabalho explora a atuação dos profissionais e os fatores que podem causar-lhes sofrimento e consequentemente, adoecimento, torna-se relevante desenvolver o presente estudo, que propiciará melhor visualização do trabalho da equipe multiprofissional de cuidados paliativos, assim como apontará a relação entre o prazer de cuidar e o desgaste emocional dos membros dessa equipe ao lidar com o processo de morrer, a morte e o luto de familiares e pacientes em cuidados paliativos.

Assim, este estudo teve como objetivos: investigar os significados apresentados pela equipe multiprofissional, bem como identificar o prazer e o sofrimento no trabalho em cuidados paliativos.

\section{METODOLOGIA}

Pesquisa exploratório-descritiva com análise qualitativa de dados. Foi teoricamente embasada na técnica de observação participante, que auxilia o pesquisador a interagir com os sujeitos da pesquisa em seu próprio ambiente. Deste modo, buscou-se compreender as representações e os conteúdos simbólicos, presentes no processo de trabalho da equipe multiprofissional, partindo da premissa de que estes interferem diretamente no aspecto cognitivo, na interpretação da realidade e nas condutas adotadas pelos profissionais.

A pesquisa foi realizada com profissionais da equipe de saúde de unidade hospitalar de cuidados paliativos no município de São Paulo, após assinarem o Termo de Consentimento Livre e Esclarecido. Os dados foram coletados nos meses de março e abril de 2010, por meio de entrevistas individuais gravadas, que foram norteadas por questões semiestruturadas e não diretivas, com o intuito de favorecer a livre expressão dos sujeitos e estimular a abordagem temática em estudo.

Os dados foram coletados no próprio hospital, em horários combinados entre a pesquisadora e os participantes da pesquisa. O conteúdo das entrevistas foi interpretado a partir da seleção dos assuntos centrais. Primeiramente, foi realizado um recorte do texto, elegendo frases ou palavras repetidas com maior frequência, ou colocadas com mais ênfase pelos participantes do estudo. Em seguida, as palavras ou frases selecionadas foram codificadas em temas geradores, a partir dos quais se definiram as categorias de análise. A amostra foi definida a partir da saturação dos dados.

Os dados foram analisados segundo a proposta de análise temática de Minayo; ${ }^{5}$ fundamentada nos preceitos de prazer e sofrimento no trabalho determinado por Dejours ${ }^{3}$ e ainda, os dados foram confrontados com a literatura sobre o tema.

O estudo foi aprovado pelo Comitê de Ética e pela administração da instituição em estudo, sob parecer $n^{\circ} 170 / 2009$, e seguiu todas as normas da Resolução no 196/96, referente à ética em pesquisa com seres humanos. Para respeitar o anonimato dos participantes, seus nomes foram substituídos por nomes de flores.

\section{RESULTADOS E DISCUSSÃO}

Foram entrevistados 18 indivíduos da equipe multiprofissional que prestavam assistência a pacientes em cuidados paliativos e a seus familiares. $O$ sexo predominante dos participantes foi o feminino (94,44\%). A amostra contou com três médicos, duas enfermeiras, duas fisioterapeutas, uma terapeuta ocupacional, uma psicóloga, uma fonoaudióloga, uma orientadora espiritual, cinco técnicos de enfermagem e duas cuidadoras formais. Os profissionais de nível superior totalizaram 55,55\% da amostra; e $44,45 \%$ eram profissionais de nível médio.

As categorias de análise observadas na pesquisa foram: significados apresentados pelos profissionais em relação ao trabalho; fontes de 
prazer relacionadas à qualidade da assistência prestada aos pacientes em cuidados paliativos e aos seus familiares; e sofrimento da equipe multiprofissional.

Sobre a categoria "significados apresentados pelos profissionais em relação ao trabalho", obtiveram-se três subcategorias de análise: humanização do cuidar; satisfação pessoal no processo do cuidar; e satisfação profissional no processo do cuidar.

\section{A humanização do cuidar}

A "humanização" é definida como ato de humanizar, dar condição humana a, humanar, civilizar, tornar-se humano, humanar-se. ${ }^{6}$ Será que existe essa ação nas competências dos profissionais de cuidados paliativos? Refere-se que a essência humana está no cuidado, sendo ele o suporte da criatividade, da liberdade e da inteligência, permeadas pelos princípios, valores e atitudes presentes no agir e no viver. ${ }^{7}$

O cuidado é fundamental para a construção do processo de ser saudável, à medida que permite e estimula o indivíduo a tomar consciência de si mesmo e do mundo, a tomar a responsabilidade pela sua transformação e a participar de um mundo melhor e mais justo assim isto é, repleto de qualidade de vida. O grande desafio dos profissionais da saúde é cuidar do ser humano na sua totalidade, exercendo uma ação preferencial em relação a sua dor e ao seu sofrimento, nas dimensões física, psíquica, social e espiritual, com competência tecnocientífica e humana. ${ }^{8}$

Destaca-se que, ao manter o contato com o paciente, algumas vezes, com um simples gesto ou olhar, o profissional passa a mensagem silenciosa de que além de se importar com o que ele está falando, interessa-se por seus sentimentos e perturbações. Preocupa-se com o paciente como ser humano que possui sentimentos e emoções, e não apenas com um sintoma ou um órgão comprometido - isso pode facilitar o cuidado integral e humanizado. ${ }^{9}$
A fala a seguir ilustra como um dos entrevistados percebe a humanização do cuidar.

Representa uma forma de olhar a medicina, a assistência à saúde, no cuidar e especialmente, no cuidar e não no curar. Representa olbar para o paciente e para a família como um ser biográfico, e não biológico que tem uma história de vida, que tem todos os seus méritos e suas fragilidades físicas, emocionais e espirituais. (Flor de Maio).

Todos os seres humanos têm o direito de cuidar-se e de serem cuidados. Nesse contexto, torna-se relevante a valorização do paciente e de sua família. Assim, proporcionar os cuidados paliativos é atendê-los na sua integralidade; a atitude do profissional supera sua habilidade técnica e o conhecimento científico, predominando sua forma de agir como pessoa como Ser existencial.

Dentro da perspectiva do cuidado, é fundamental que o paliativista tenha a habilidade do cuidar. No entanto, só se adquire essa habilidade quando se cuida e, cada vez mais, esse profissional irá descobrir novas maneiras de cuidar e, com certeza, esse despertar do fazer sempre o melhor promoverá a competência desse profissional.

\section{Satisfação pessoal no processo do cuidar}

É de extrema importância que o profissional se identifique com seu trabalho e perceba que ele lhe traz a satisfação pessoal.

Este trabalho é uma experiência, um campo de trabalho que me enriquece a cada dia. É um trabalho difícil, mas me dá ânimo para levantar todo dia de manhã. Trabalhar em cuidados paliativos representa realização, praẓer, atuação. É o que me representa. (Estrelita).

A organização do trabalho é potencialmente patogênica, mas existem trabalhadores que conseguem reduzir, ou pelo menos evitar, o sofrimento no trabalho, considerando que o prazer e sofrimento podem resultar de fatores 
relativamente independentes. Nesse momento, surge o trabalho equilibrante. ${ }^{4}$

Nesta abordagem, o ser humano é essencial e sua conduta é explicada e significada por causa dos vínculos criados entre o indivíduo com outros seres humanos..$^{10}$ Assim, em cuidados paliativos, o aspecto positivo advindo do cuidar atenua o sofrimento do profissional.

\section{Satisfação profissional no processo do cuidar}

É muito difícil separar a satisfação pessoal da satisfação profissional, pois elas em geral são interdependentes.

É eu me dedicar. Eu conto com o cuidador junto que percebe o atendimento, ou seja, está ali presente. Eu me dedico, mostro, converso, eu brinco, converso como se ele estivesse respondendo pra mim, mesmo que não responda. Resumindo tudo, é o amor que tenho pela minha profissão e tenho por ele. (Amarílis).

Para os pacientes em cuidados paliativos, o relacionamento humano é a essência do cuidado que sustenta a fé e a esperança nos momentos mais difíceis. Expressões de compaixão e afeto na relação com o outro trazem a certeza de que somos parte significante de um conjunto, o que traz a sensação de consolo e realização, além de paz interior. ${ }^{8}$

Salienta-se que o "prazer e sofrimento são vivências subjetivas, que implicam um ser de carne e um corpo onde ele se exprime e se experimenta da mesma forma que a angústia, o desejo e o amor". ${ }^{4}$ Nesta abordagem, uma equipe composta por profissionais satisfeitos reflete a busca pela aquisição de novos conhecimentos que vão além de suas áreas de atividade e um atendimento de maior qualidade ao usuário dos serviços de saúde.?

Assim, a intersubjetividade se reflete na satisfação pessoal de cada membro que ocupa um lugar dentro da equipe multiprofissional, uma vez que sua atuação e satisfação com o trabalho realizado podem interferir de maneira significativa na atenção prestada ao paciente, família e equipe multiprofissional.

$\mathrm{Na}$ segunda categoria intitulada - prazer relacionado à qualidade da assistência prestada aos pacientes, aos seus familiares e ao trabalho da equipe multiprofissional em cuidados paliativos -, destacam-se as seguintes subcategorias: qualidade da assistência prestada aos pacientes em cuidados paliativos; qualidade da assistência prestada aos familiares de pacientes em cuidados paliativos; e fontes de prazer relacionadas à equipe multiprofissional de cuidados paliativos.

Qualidade da assistência prestada aos pacientes em cuidados paliativos

Os profissionais sentem-se satisfeitos com o alcance da qualidade do serviço prestado.

A gente sente quando está feliz e está fazendo alguma
coisa para eles. Mesmo com um olhar de alguma forma
eles percebem e respondem de alguma forma. O paciente
recebe alta, a gente sente como se ele dissesse "vou deixar
vocês". A gente cria um laço de amiz̧ade. (Helicônia).

Diante disso, os pacientes nos direcionam sobre como gostariam que fosse a comunicação interpessoal no contexto da terminalidade. Valorizam a alegria, tanto em si mesmos quanto nos profissionais de saúde e nas pessoas com as quais convivem. ${ }^{11}$ Nesse sentido, é imprescindível um controle do tratamento,prestado ao paciente no final da vida, que seja desprovido de agressividade e aliado à atenção despendida aos familiares desse paciente; por isso a habilidade eficaz desse manejo é um desafio a ser alcançado pelos profissionais do século XXI. ${ }^{12}$ É fundamental que o trabalho retribua condições favoráveis quando o profissional está circundado de sofrimento, assim favorecendo seu equilíbrio mental. ${ }^{3}$

As falas dos entrevistados denotam que a melhora do paciente é vista como uma fonte de prazer, pois esses participantes a consideram como o resultado de seus trabalhos, tanto relacionado à competência técnica quanto à competência do ser. 
Qualidade da assistência prestada aos familiares de pacientes em cuidados paliativos

É visível a gratidão dos profissionais decorrente das respostas positivas que os familiares transmitem após os cuidados prestados ao paciente.

É muito bonito quando você cuida de um paciente, ai a familia chega e fala: nossa, ele entrou aqui no hospital de tal forma e agora já está melhorando! Porque en cuidei, alguém cuidou, então, nessa parte de recuperação, os familiares ajudam muito. (Gérbera).

Ao conviver com os familiares de pacientes fora de possibilidades terapêuticas, os profissionais de saúde precisam ter certo grau de amadurecimento, principalmente ao conversar com esses familiares. Esse amadurecimento resulta da vivência, do grau de envolvimento e da conscientização desse profissional, pois só assim a análise do tratamento e do prognóstico será clara e consistente, enfocando sempre a qualidade de vida depois da alta hospitalar. ${ }^{13}$

Percebe-se que o bom relacionamento entre a equipe de saúde e familiares proporciona melhoria na assistência prestada e, ainda, na satisfação do cliente e do profissional. Vale ressaltar que o trabalho proporciona ao profissional a possibilidade de transferir sua energia pulsional para atividades que são reconhecidas socialmente. ${ }^{3,4}$

Fontes de prazer relacionado ao trabalho da equipe multiprofissional de cuidados paliativos

Nesta subcategoria, observa-se a importância da satisfação pessoal e profissional.

Não temos que escolher pelo dinheiro e sim pelo amor. $O$ dinheiro não é tudo. O que adianta você ter uma profissão que pague bem e não ser feliz naquilo que você fa\%: A gente tem que ter amor em tudo. Eu tenho amor no que faço e me sinto feliz: (Margarida).

Na percepção dos participantes, a paciência, a coragem e os esforços apresentados pelos pacientes na luta pela vida servem como exemplo, que possibilita ao cuidador oportunidades para crescimento pessoal. ${ }^{14}$

No próximo discurso, o prazer também vem a partir do trabalho em equipe.

O fato de eu conviver com uma equipe multiprofissional, com saberes diferentes, com visöes diferentes, isso pra mim é muito rico. É uma constante fonte de prazer. (Petúnia).

Nesta abordagem, a satisfação no trabalho está diretamente relacionada ao estado emocional e prazeroso, ou seja, o resultado das experiências no ambiente profissional, quando positivo, satisfaz o trabalhador, caso contrário, leva a um grau de insatisfação. ${ }^{15}$

O trabalho de cada profissional dentro da equipe multiprofissional é aprendido como um conjunto de atribuições, atividades ou tarefas. Mas uma vez que existem profissionais de diferentes áreas, que atuam juntos - cada um com um conhecimento específico -, que não levam ao conhecimento da equipe a articulação de seus trabalhos especializados, podese considerar a ausência do trabalho em equipe. ${ }^{16}$ Assim, nota-se que o trabalho em equipe possibilita o prazer entre os profissionais.

A partir da categoria "sofrimento da equipe multiprofissional", obtiveram-se as seguintes subcategorias: presença do processo de morrer e da morte; desgaste da equipe multiprofissional decorrente do sofrimento do paciente; impotência na equipe multiprofissional de cuidados paliativos; e presença de conflitos na equipe multiprofissional de cuidados paliativos.

\section{A presença do processo de morrer e da morte}

O destaque maior de relatos com relação ao sofrimento da equipe paliativista foi quanto ao processo de morrer e à morte.

Menos gratificada quando há a perda. Hoje eu posso estar aqui e amanhã não encontro mais esse paciente. Eu ainda me apego aos pacientes e realmente ainda choro muito e ainda estou buscando este equilibrio, pra mim. (Amarílis). 
Destaca-se que o trabalho se torna perigoso para o aparelho psíquico quando ele se opõe a sua livre atividade. ${ }^{3} \mathrm{O}$ profissional que trabalha em hospital sabe que há pacientes especiais, com os quais estabelece uma relação diferenciada. A morte desses pacientes provoca luto, com todas suas reações próprias, como se fosse por uma pessoa com a qual mantivesse relações de outra ordem que não a profissional. ${ }^{17}$

Nesse aspecto, enfatiza-se que a morte está atrelada ao consciente e também ao inconsciente, tratando-se tanto de um fato biológico quanto humano. A aceitação dessa fase do ciclo vital, a morte, pode ser considerada como um dos maiores sinais de maturidade humana. ${ }^{18}$

Salienta-se que o sofrimento do profissional frente à morte do paciente pode ser amenizado, a partir do momento da conscientização do seu máximo desempenho profissional e a comunicação na equipe multiprofissional relacionada à discussão da complexidade dos casos clínicos assistidos pela equipe.

\section{0 desgaste da equipe multiprofissional decorrente do sofrimento do paciente}

Esta fala indica o desgaste da equipe:

$$
\begin{aligned}
& \text { "Sofrimento é eu não conseguir dar conta. Sofrimento é } \\
& \text { eu ver o paciente sofrer e não conseguir ajudar, ele sofre } \\
& \text { e você sofre junto!" (Cravo). }
\end{aligned}
$$

Frente a isso, tem-se que a estrutura mental de cada indivíduo é constituída por um conjunto de caracteres supostamente invariáveis e estáveis, que determina a forma como poderá encarar a doença mental, na presença de descompensação do equilíbrio, entre as pressões do trabalho (excessivas) e as possibilidades defensivas (transbordadas) do indivíduo. Nessa linha de abordagem, o enfrentamento de situações estressantes depende das condições mentais da pessoa. ${ }^{4}$

Embora o hospital exista para salvar vidas e recuperar a saúde dos indivíduos doentes, tal missão pode propiciar desequilíbrio no estado de saúde de seus trabalhadores, por se tratar de um ambiente insalubre e penoso. ${ }^{14,19}$ Pensando assim, é de fundamental importância valorizar as condições, tanto físicas como mentais, desses profissionais que prestam assistência aos familiares/pacientes em cuidados paliativos em instituições hospitalares, pois só a partir do equilíbrio desses aspectos é que esses profissionais conseguirão desempenhar seus papéis da melhor maneira possível, sem causar prejuízos a sua saúde.

A impotência na equipe multiprofissional de cuidados paliativos

O desgaste no trabalho foi demarcado pelo sentimento de impotência, visto que em alguns momentos os profissionais não conseguem proporcionar ao paciente tudo aquilo de que ele necessita, tal como foi notado na fala a seguir:

Eu acho que o mais sofrido é o sentimento de impotência, por não ter ajudado o suficiente. O sentimento de impotência por algo que você gostaria de fazer ou que fosse feito por aquele doente ou algo que você deveria, mas que está fora do nosso alcance. (Orquídea).

No momento em que existe a sobrecarga de trabalho, pode-se falar em "sofrimento patogênico", encarado como o sofrimento que emerge quando todas as possibilidades de adaptação ou de ajustamento à organização do trabalho pelo sujeito, colocadas em concordância com seu desejo, foram utilizadas, e a relação subjetiva com a organização do trabalho está bloqueada. ${ }^{4}$

Também podem existir dois sintomas decorrentes do sofrimento no trabalho; um deles é a insatisfação, representada pelo conteúdo significativo do trabalho tanto relacionado ao sujeito, quanto relacionado ao objeto, pelo conteúdo simbólico e, ainda, marcada pelo conteúdo ergonômico, que está atrelado ao exercício do corpo, no sentido físico e nervoso. ${ }^{3}$

Perante o reconhecimento desse sofrimento, é essencial que o profissional reconheça seu limite e procure ajuda, tanto para suprir o desgaste físico quanto o mental. 
A presença de conflitos na equipe multiprofissional de cuidados paliativos

Vale aqui ressaltar que o conflito presente no trabalho em equipe foi destacado como causador do desequilíbrio emocional do profissional, que pode levar à alteração no clima organizacional.

Quando um da minha equipe multidisciplinarinterpreta alguma coisa errada ou se acontece alguma coisa, ab! Não tem aquela, conversa. Eu fico muito chateada com isso. [...] Geralmente acaba se resolvendo, com uma boa conversa, mas fica sempre aquele "arzinbo", do tipo virando a cara, entendeu ab! (Amarilis).

Dependendo de posicionamentos filosóficos, de experiências anteriores, do papel que o profissional desempenha na equipe e da disciplina de cada um, pode haver formas diferentes de lidar com o estresse. Este pode ser um elemento de conflito dentro da equipe, quando determinado profissional ou grupo de profissionais não aceitarem a posição de outros. ${ }^{20}$

Quanto às representações circundantes e às questões relativas ao trabalho, estas estão marcadas pelas concepções apreendidas junto a diversos aspectos do objeto de trabalho propriamente dito, e pelas posições que distintas categorias profissionais elaboram sobre o mesmo.

Estudos desenvolvidos na perspectiva da psicodinâmica mostraram que os trabalhadores de diferentes categorias profissionais apresentavam relatos de sofrimento diante do trabalho. Tais insatisfações denotam desajustes, conflitos entre os desejos do sujeito trabalhador e os produtos ou resultados do trabalho. ${ }^{3,4}$ Pensando assim, alguns conflitos resultam do abuso do poder relacionado à hierarquia dentro das instituições, e isso pode levar os profissionais a apresentarem sofrimento no trabalho.

As possíveis limitações desta pesquisa podem ser representadas pela não sistematização do grupo amostral (amostra de conveniência) e devido à amostra ter sido coletada em uma única instituição, o que não permite a generalização dos resultados. Por outro lado, os resultados possibilitam identificar a importância de estudos dessa natureza junto aos profissionais que atuam em cuidados paliativos.

\section{CONSIDERAÇÕES FINAIS}

A sensibilidade da equipe multiprofissional demonstra a humanização no processo de cuidar e a importância da integralidade do cuidado.

No tema que trata do "prazer relacionado à qualidade da assistência prestada aos pacientes em cuidados paliativos e seus familiares", observa-se o aspecto da qualidade da assistência prestada, segundo a qual o profissional consegue atingir seu objetivo de cuidar com amor quando adquire a resposta positiva do paciente e de seus familiares. Nota-se que o prazer relacionado ao processo de cuidar se faz presente no convívio diário desses profissionais durante a prestação da assistência.

Na categoria "sofrimento da equipe de saúde", percebe-se que este é reflexo do sofrimento do paciente; a equipe que o assiste dentro de sua impotência operacional participa dessa angústia, às vezes promovendo conflitos decorrentes de tal desgaste.

Diante de todos esses eventos de prazer e sofrimento no trabalho, juntamente do zelo ao paciente em cuidados paliativos e seus familiares, os profissionais elaboram estratégias de enfrentamento para levar adiante sua tarefa de cuidar com humanidade.

Salienta-se que os resultados desta pesquisa são específicos para a equipe multiprofissional estudada. Dessa maneira, se faz necessário realizar estudos relacionados às estratégias de enfrentamento assumidas pela equipe paliativista que assiste o binômio familiares/paciente em cuidados paliativos.

Assim, espera-se contribuir para a melhoria relacionada ao prazer e sofrimento no trabalho de profissionais em cuidados paliativos. Deve-se repensar os ambientes de trabalho, almejando as possibilidades de amenizar as insatisfações e elevar os ganhos advindos da prestação da assistência aos familiares e pacientes em cuidados paliativos. 


\section{REFERÊNCIAS}

1. Matsumoto DY. Cuidados paliativos: conceitos, fundamentos e princípios. In: Academia Nacional de Cuidados Paliativos. Manual de cuidados paliativos. Rio de Janeiro: Diagraphic ; 2006, p. 14-19.

2. World Health Organization. Better palliative care for older people. Geneva: WHO; 2004.

3. Dejours C. A loucura do trabalho: estudo de psicopatologia do trabalho. São Paulo: Cortez ; 1992.

4. Dejours C, Abdoucheli E, Jayet C. Psicodinâmica do trabalho: contribuições da Escola Dejouriana à análise da relação prazer, sofrimento e trabalho. São Paulo: Atlas; 1994. p. 119-45.

5. Minayo MCS. O desafio do conhecimento: pesquisa qualitativa em saúde. 8. ed. São Paulo: Hucitec, 2004.

6. Ferreira ABH. Mini Aurélio: o minidicionário da língua portuguesa. Rio de Janeiro: Nova Frontreira; 2000.

7. Boff L. Saber cuidar: ética do humano, compaixão pela terra. 4. ed. Petrópolis: Vozes; 1999.

8. Bettinelli LA, Waskievicz J, Erdmann AL. Humanização do cuidado no ambiente hospitalar. In: Pessini L, Bertachini L, organizadores. Humanização e cuidados paliativos. 3. ed. São Paulo: Loyola, 2006. p. $87-100$.

9. Papaléo Netto M, Yuaso DR. Interdisciplinaridade em gerontologia: aspectos conceituais e objetivos. In: Papaléo Netto M, organizador. Tratado de gerontologia. 2. ed. rev. e ampl. São Paulo: Atheneu; 2007. p. 149-62.

10. Bleger J. Psico-higiene e psicologia institucional. Porto Alegre: Artes Médicas; 1984.

11. Araújo MMT, Silva MJP. A comunicação com o paciente em cuidados paliativos: valorizando a alegria e o otimismo. Rev Esc Enferm USP 2007;41(4):668-74.

12. Prendergast TJ, Claessens MT, Luce JM. A National Survey of En-of-life Care for Critically ill Patients. Am J Respir Crit Care Med 1998;158(4):1163-7.

13. Gutierrez BAO. O processo de morrer no cotidiano do trabalho dos profissionais de enfermagem de unidades de terapia intensiva [tese]. São Paulo: Universidade de São Paulo; 2003.

14. Shimizu HE, Ciampone MHT. Sofrimento e prazer no trabalho vivenciado pelas enfermeiras que trabalham em unidades de terapia intensiva em um hospital escola. Rev Esc Enferm USP 1999;33(1):95-106.

15. Locke EA. The nature and causes of job satisfaction. In: Dunnete MD, editor. Handbook of industrial and organizational psychology. Chicago: Rand McNally; 1976. p.1297-349.

16. Peduzzi M. Equipe multiprofissional de saúde: conceito e tipologia. Rev. Saúde Pública 2001;35(1):103-9.

17. Franco MHP. Cuidados paliativos e o luto no contexto hospitalar. In: Pessini L, Bertachini L, organizadores. Humanização e cuidados paliativos. 3. ed. São Paulo: Loyola; 2006. p. 301-04.

18. Py L, Oliveira AC. Humanizando o adeus à vida In: Pessini L, Bertachini L, organizadores. Humanização e cuidados paliativos. 3. ed. São Paulo: Loyola; 2006. p. $135-48$.

19. Lima Júnior JHV, Ésther AB. Transições, prazer e dor no trabalho de enfermagem. Rev Adm Empres 2001;41(3):20-30.

20. Carvalho VA. Cuidados com o cuidador. In: Pessini L, Bertachini L, organizadores. Humanização e cuidados paliativos. 3. ed. São Paulo: Loyola; 2006. p. 305-19. 